\title{
A study of the risk factors related to ectopic pregnancy in intrauterine device users
}

\author{
Jian Zhou ${ }^{1}$, Yue-hua Yang ${ }^{1}$, Zhi-ming Sun ${ }^{1}$, Ying Li ${ }^{* 2}$ \\ ${ }^{1}$ Jiangsu Institute of Planned Parenthood Research, Nanjing, China \\ ${ }^{2}$ School of Public Health, Nanjing Medical University, Nanjing, China
}

Received: January 19, 2017

Accepted: July 2, 2017

Online Published: July 18, 2017

DOI: $10.5430 /$ jer.v3n2p40

URL: https://doi.org/10.5430/jer.v3n2p40

\begin{abstract}
Objectives: Analysis of the risk factors related to ectopic pregnancy (EP) among intrauterine device (IUD) users in order to reduce the risk of EP from IUD users and to safeguard women's health.

Methods: A total of $29 \mathrm{EP}$ cases were collected and 1:1 matched controls in IUD users by case-control study.

Results: The data showed that pregnancies had significant association with EP, two pregnancies and three or more pregnancies were increased the risk of $\mathrm{EP}$, adjusted odds ratio $A O R=14.39,95 \% \mathrm{CI}: 2.37,87.49$ and $A O R=14.87,95 \% \mathrm{CI}: 2.27,97.38$ respectively. The risk of $\mathrm{EP}$ in women of previous abdominal or pelvic surgery was also significantly increased $(A O R=4.43,95 \%$ CI: 1.04, 18.92). While no significant association have been seen with age, first or second time use IUD, periods of insertion, types of IUD, and copper surface area of IUD.

Conclusion: The results suggest that the number of pregnancies significantly increase the risk of EP, there is no significant association between the risk of EP and copper surface area or shape of IUD used. Therefore, a woman's individual risk factors will lead to a rise in the risk of EP, there is a need to the suitability of her contraceptive. It is beneficial to reduce the risk of EP by the prevention of unwilling pregnancy and induced abortion.
\end{abstract}

Key Words: Intrauterine device, Ectopic pregnancy, Case control study, Risk factors

\section{INTRODUCTION}

As long-term contraceptive, intrauterine device (IUD) has become the most commonly used method in China. ${ }^{[1]}$ The number of women using IUD in China accounted for about $70 \%-80 \%$ of worldwide. IUDs can prevention and control of pregnancy. Meanwhile, they can inevitably cause health risks, such as ectopic pregnancy (EP) in IUD users, which belong to serious adverse outcomes. That harms themselves are difficult to eliminate, need surgery to alleviate the damage, so the safety of IUD is especially important. In this study, a case-control study was designed to identify potential risk in order to reduce the incidence of $\mathrm{EP}$, and to provide a reference for the safe use in IUD users.

\section{MethodS}

This study was conducted at sentinel hospitals (county) in China. The study protocol was approved by Jiangsu Institute of Planned Parenthood Research. All subjects gave signed informed consent.

From Jan to Dec 2014, EP cases with IUD were enrolled as subjects in the case group (EP group) at sentinel hospitals. Women using IUD at the same sentinel hospital matched for age ( \pm 3 years), time of inserting IUD ( \pm 3 months), using IUD without any event were added to the control group.

The information of research was collected from all subjects (by interview and medical records) which included socio-

*Correspondence: Ying Li; Email: liying2008@qq.com; Address: School of Public Health, Nanjing Medical University, Nanjing 211166, China. 
demographic features, history of contraception, birth history, surgical history, history of pelvic inflammatory disease (PID), IUD product information, insertion period, individual biological characteristics, placing IUD operation information.

Data was entered into computers by two independent staff. Univariate logistic regression was analyzed to the difference of the risk factors between the two group, including the crude odds ratio $(O R)$ and $95 \%$ confidence interval $(C I)$. A multivariable logistic regression analysis was used to adjust for confounders and calculate adjusted odds ratio (AOR). All statistical analysis was performed with SAS software, version 9.3 (SAS Institute, Inc., Cary, NC). Significance level was set at $p<.05$.

\section{RESUltS}

A total of $29 \mathrm{EP}$ cases and 29 controls among IUD users were collected in this study. The diagnoses of EP were made on the basis of history, ultrasonography, and level of $\beta$-human chorionic gonadotropin. The cases included 12 left tubal pregnancies, 15 right tubal pregnancies, 2 cases of unknown. The average age of EP group was $29.86 \pm 4.99$ years, while the control group was $30.14 \pm 4.82$ years, two groups of age distribution were compared without statistically significant. Meanwhile the difference between two groups was not statistically significant in occupation, education level, marital status and marriage age.

The results of the analysis were shown in Table 1. The data revealed that history of abdominal or pelvic surgery was associated with risk of EP $(A O R=4.43,95 \% C I: 1.04$, 18.92). Two pregnancies and three or more pregnancies had a significant higher risk of EP $(A O R=13.93,95 \% C I: 2.45$, $79.21 ; A O R=15.00,95 \% C I: 2.65,84.78)$ compared with one pregnancy. However, there were no significant correlated between the risk of EP and factors including uterus position, first or second time use IUD, period insertion of IUD, shapes of IUD, and copper surface area of IUD.

\section{Discussion}

EP is the leading cause of maternal mortality in the first trimester of pregnancy. ${ }^{[2]}$ It has been accounted for about $1 \%-2 \%$ of all naturally pregnancies. ${ }^{[3]}$ In the past decades, the occurrence of EP has been on the rise in many countries. ${ }^{[4,5]}$

Table 1. Risk factors for EP in IUD users

\begin{tabular}{|c|c|c|c|c|c|c|}
\hline \multirow{2}{*}{ Factors } & \multicolumn{2}{|c|}{ Case group } & \multicolumn{2}{|c|}{ Control group } & \multirow{2}{*}{ OR $[95 \% C I]$} & \multirow{2}{*}{$A O R[95 \% C I]$} \\
\hline & $n$ & $\%$ & $n$ & $\%$ & & \\
\hline \multicolumn{7}{|l|}{ Pregnancies } \\
\hline 1 & 2 & 6.90 & 15 & 51.72 & Reference & Reference \\
\hline 2 & 13 & 44.83 & 7 & 24.14 & $13.93[2.45,79.21]$ & $14.39[2.37,87.49]$ \\
\hline$\geq 3$ & 14 & 48.28 & 7 & 24.14 & $15.00[2.65,84.78]$ & $14.87[2.27,97.38]$ \\
\hline \multicolumn{7}{|l|}{ Previous pelvic surgery } \\
\hline No & 19 & 65.52 & 26 & 89.66 & Reference & Reference \\
\hline Yes & 10 & 34.48 & 3 & 10.34 & $4.56[1.10,18.86]$ & $4.43[1.04,18.92]$ \\
\hline \multicolumn{7}{|l|}{ Uterus position } \\
\hline Middle & 8 & 27.59 & 8 & 28.57 & Reference & Reference \\
\hline Anteversion & 17 & 58.62 & 12 & 42.86 & $0.71[0.21,2.41]$ & $0.62[0.15,2.55]$ \\
\hline Retroversio & 4 & 13.79 & 8 & 28.57 & $0.35[0.09,1.45]$ & $0.36[0.08,1.52]$ \\
\hline \multicolumn{7}{|l|}{ First-time user } \\
\hline Yes & 15 & 51.72 & 13 & 44.83 & Reference & Reference \\
\hline No & 14 & 48.28 & 16 & 55.17 & $0.76[0.27,2.13]$ & $0.59[0.17,1.99]$ \\
\hline \multicolumn{7}{|l|}{ Period insertion of IUD } \\
\hline Menstrual interval & 25 & 86.21 & 24 & 82.76 & Reference & Reference \\
\hline After induced abortion & 2 & 6.90 & 3 & 10.34 & $0.64[0.10,4.17]$ & $0.69[0.10,4.88]$ \\
\hline Suckling period & 2 & 6.90 & 2 & 6.90 & $0.96[0.13,7.37]$ & $0.86[0.10,7.10]$ \\
\hline \multicolumn{7}{|l|}{ Shapes of IUD } \\
\hline Open frames & 17 & 58.62 & 17 & 58.62 & Reference & Reference \\
\hline Closed frames & 11 & 37.93 & 10 & 34.48 & $1.10[0.37,3.27]$ & $1.17[0.38,3.61]$ \\
\hline Fixed & 1 & 3.45 & 2 & 6.90 & $0.50[0.04,6.05]$ & $0.53[0.04,6.75]$ \\
\hline \multicolumn{7}{|c|}{ Copper surface area of IUD } \\
\hline$<300 \mathrm{~mm}^{2}$ & 24 & 82.76 & 24 & 82.76 & Reference & Reference \\
\hline$\geq 300 \mathrm{~mm}^{2}$ & 5 & 17.24 & 5 & 17.24 & $1.00[0.26,3.91]$ & $0.93[0.23,3.74]$ \\
\hline
\end{tabular}


IUD is widely used as a long-acting contraceptive in China, but whether to increase the risk of EP is still controversial. Some studies found that past use of IUD could mildly increase the risk of EP. ${ }^{[6,7]}$ Other study recently found that current IUD use play dominant roles in the occurrence of EP. ${ }^{[8]}$ The main reason may be pelvic infections, which could cause an ectopic implantation among past IUD users. ${ }^{\left[{ }^{[]}\right.}$According to guideline of American College of Obstetricians and Gynecologists (ACOG), using IUD does not increase the absolute risk of EP. But "if pregnancy does occur with an IUD in place, the pregnancy is more likely to be ectopic". ${ }^{\text {10] }}$ The EP incidences after using different IUD were different. In 1987, WHO pointed out that the highest incidence of EP was IUD release of progesterone, which may affect tubal peristalsis. While TCu380A and MLCu375 IUD with larger copper showed the lowest rate of EP. ${ }^{[11]}$ Skjeldestad found that copper IUD can prevent $91 \% \mathrm{EP}$, the results suggested that when $\mathrm{Cu}^{2+}$ concentration increased in the uterine cavity and fallopian tube, intrauterine pregnancy not only can be prevented, EP also can be prevented ${ }^{[12]}$ Our study suggest that there was no significant association between copper surface area, shape of IUD and the risk of EP.

In our study the risk of EP for women who conceived two or more pregnancies was 14 times fold than those who only one pregnancy and the association was statistically significant. Our results demonstrate that the risk of EP was positive correlated with pregnancies, which is similar to findings of two studies. ${ }^{[13,14]}$ Induced abortion is only a remedy for contraceptive failure, and it should not be used as a routine birth control method. But recently the times of induced abortion increase gradually especially in young unmarried women without childbearing demand. But whether induced abortion increases the risk of EP is still in arguments. Some studies believed that induced abortion did not increase the risk of EP. ${ }^{[13,15]}$ But other studies showed that there was a positive correlation between the number of abortion and EP. ${ }^{[16,17]}$
On the one hand, some researchers believed that induced abortion may lead to some complications such as endometrial lesion and intrauterine adhesion, which may affect the implantation of fertilized egg in the uterus and reduce the pregnancy rate finally. And on the other hand, some researchers believed that EP was related not to abortion itself, but rather to intrauterine infection after abortion. Induced abortion may increase the risk of reproductive tract infection (RTI), and the risk was also increased with the number of induced abortion. ${ }^{[18-20]}$

\section{Conclusions}

The study suggest that the number of pregnancies significantly increase the risk of EP, there is no significant association between the risk of EP and copper surface area or shape of IUD used. Therefore, a woman's individual risk factors will lead to a rise in the risk of EP, there is a need to the suitability of her contraceptive. It is beneficial to reduce the risk of EP by the prevention of unwilling pregnancy and abortions.

\section{ACKNOWLEDGementS}

We acknowledge the women who participated in this study, and the physicians of some county, such as Guangdong Nanhai, Jiangsu Zhangjiagang, Hubei Zhongxiang and so on, who were involved in recruiting and investigating subjects. The authors are grateful to Jie Yao, Ying Chen, Min Zhang, Jie Lin and Xue-ning Zhang for quality control of the investigation, and also grateful to Wen-hui Shi for helping data entry and analyses. This study was funded by the National Natural Science Foundation of China (Project No. 81573227) and the youth medical key project of Jiangsu province (No. QNRC2016556).

\section{CONFLicts OF InTEREST Disclosure}

The authors declare that they have no competing interests.

\section{REFERENCES}

[1] Zheng X, Tan L, Ren Q, et al. Trends in contraceptive patterns and behaviors during a period of fertility transition in China: 1988-2006 Contraception. 2012; 86: 204-213. https ://doi.org/10.1016/ j. contraception. 2011.12.006

[2] Farquhar CM. Ectopic pregnancy. Lancet. 2005; 366: $583-$ 591. PMid:22465114 https://doi.org/10.1016/S0140-673 6(05) 67103-6

[3] Shaw JL, Dey SK, Critchley HO, et al. Current knowledge of the aetiology of human tubal ectopic pregnancy. Hum Reprod Update. 2010; 16: 432-544. PMid:20071358 https://doi .org/10.1093/ humupd/dmp057
[4] Nama V, Manyonda I. Tubal ectopic pregnancy: diagnosis and management. Arch Gynecol Obstet. 2009; 279: 443-53. PMid:18665380 https ://doi.org/10.1007/s00404-008-0731-3

[5] Leke RJ, Goyaux N, Matsuda T, et al. Ectopic pregnancy in Africa: a population-based study. Obstet Gynecol. 2004; 103: 692-697. PMid:15051561 https://doi.org/10.1097/01.A0G.0000120 $146.48098 . \mathrm{f} 2$

[6] Li C, Zhao WH, Meng CX, et al. Contraceptive use and the risk of ectopic pregnancy: a multi-center case-control study. PLoS ONE. 2014; 9: e115031. PMid:25493939 https ://doi.org/10.1371/ journal.pone.0115031

[7] Risk factors in ectopic pregnancy and differences between adults and 
adolescents, is consanguinity important? J Obstet Gynaecol. 2016 Oct; 36(7): 935-939. PMid:27188852 https ://doi . org/10.108 $0 / 01443615.2016 .1174828$

[8] Li C, Zhao WH, Zhu Q, et al. Risk factors for ectopic pregnancy: a multi-center case-control study. BMC Pregnancy Childbirth. 2015 Aug 22; 15: 187. PMid:26296545 https://doi.org/10.1186/ s12884-015-0613-1

[9] Bouyer J, Rachou E, Germain E, et al. Risk factors for extrauterine pregnancy in women using an intrauterine device. Fertil Steril. 2000; 74: 899-908. https://doi.org/10.1016/S0015-0282(00) 016 05-8

[10] ACOG Practice Bulletin No. 121: Long-acting reversible contraception: Implants and intrauterine devices. Obstet Gynecol. 2011; 118: 184-196. PMid:21691183 https://doi .org/10 1097/AOG . ob013e318227f05e

[11] Irving Sivi. Center for biomedical research. The population council. Extrauterine pregnancies and intrauterine devices rearssessed. 1993. 195-209 p.

[12] Skjeldestad FE. How effectively do copper intrauterine devices prevent ectopic pregnancy? Acta Obstet Gynecol Scand. 1997; 76(7): 684-690. PMid:9292645 https ://doi .org/10.3109/00016349 709024611

[13] Moini A, Hosseini R, Jahangiri N, et al. Risk factors for ectopic pregnancy: A case-control study. Journal of Research in Medical Sciences. 2014; 19(9): 844-849. PMid:25535498
[14] Barnhart KT, Sammel MD, Gracia CR, et al. Risk factors for ectopic pregnancy in women with symptomatic first trimester pregnancies. Fertil Steril. 2006; 86: 36-43. PMid:16730724 https: //doi.org/10.1016/j.fertnstert.2005.12.023

[15] Khedar S, Mital P, Rajoria L, et al. A case-control study to evaluate risk factors for ectopic pregnancy. Int J Reprod Contracept Obstet Gynecol. 2016 Aug; 5(8): 2828-2835. https://doi .org/10.182 03/2320-1770.ijrcog20162675

[16] Li Xue, You Hong, Yuan Xiao-qian. Analysis of Related Risk Factors of Ectopic Pregnancy.Chinese and Foreign Medical Research. 2015; 13(14): 5-7.

[17] Bouyer J, Coste J, Shojaei T, et al. Risk factors for ectopic pregnancy: a comprehensive analysis based on a large case-control, populationbased study in France. Am J Epidemiol. 2003 Feb 1; 157(3): 185-194. PMid:12543617 https://doi .org/10.1093/aje/kwf 190

[18] Goto A, Nguyen QV, Pham NM, et a1. Prevalence of and factors associated with reproductive tract infections among pregnant women in ten communes in Nghe An province, Vietnam. Journal of Epidemiology. 2005; 15(5): 163-172. PMid:16195636 https : //doi.org/10.2188/jea.15.163

[19] Zhang RJ, Zhang XJ, Lv XJ, et al. Study on the correlation between induced abortion and reproductive tract infections. Zhonghua Liu Xing Bing Xue Za Zhi. 2011 Jan; 32(1): 29-32. PMid:21518537

[20] Yang Li, Huang Xing, Bai Fu. Correlation of reproductive tract infections and other influencing factors with induced abortion. Chin J Public Health. Apr 2014; 30(4): 416-419. 